Trab. Ling. Aplic., Campinas, 44(2): 265-276, Jul./Dez. 2005

\title{
"É, EU ACHO QUE ESSE LIVRINHO VAI SER MUITO INTERESSANTE." VOZES DE PROFESSORES INDÍGENAS EM UM CURSO DE FORMAÇÃO
}

\author{
MARILDA C. CAVALCANTI \\ (Unicamp)
}

\begin{abstract}
RESUMO
Minha trajetória acadêmica tem início com as memórias evocadas das primeiras aulas no curso de mestrado em Lingüística Aplicada da PUC-SP. E com essas memórias vem a imagem do primeiro professor e, depois, meu orientador nesse curso - John Schmitz - que com sua vitalidade fazia com que nós alunos trabalhássemos de forma incomensurável e nos guiava pelas teorias que embasavam as pesquisas em Lingüística e Lingüística Aplicada e pelas práticas que geravam teorias de ensino/aprendizagem. As primeiras discussões sobre Lingüística Aplicada, o encantamento com a área, tudo isso vem dessa época. Não poderia, portanto, deixar de apresentar aqui uma contribuição relativa à produção de material didático na formação de professores para esta publicação em homenagem a essa figura humana tão admirável.
\end{abstract}

Palavras-chave: lingüística aplicada, material didático, formação de professores, interação, transcultural.

\begin{abstract}
Although Brazilian native ethnic groups have shelter in the Brazilian Constitution, they have to struggle to maintain their traditions and language within the dominant society which sees itself as monolingual in Portuguese. The ethnic groups have strong support from pro-indigenous NGOs. One of these NGOs, the CPI/Ac, develops an educational program which includes an intensive indigenous teacher education course. About thirty young men belonging to ten different ethnic groups attend this annual course where Portuguese is a lingua franca and medium of instruction. This paper is based on an ethnographic study whose data come from the cross-cultural interaction between the non-indigenous teacher educators and twelve of these Brazilian native teachers. The data analyzed were recorded during a language methodology class while the teachers were discussing the preface for a textbook they had put together. The focus of the analysis is the interface of voices as related to identity construction.
\end{abstract}

Key-words: applied linguistics, textbook, interaction, cross-cultural.

\section{INTRODUÇÃO}

Inserido em um projeto de pesquisa que abriga vários subprojetos, este estudo, de cunho etnográfico, investiga uma interação transcultural no contexto de um curso de formação de professores indígenas na região norte do país. O objetivo do texto é trazer o holofote para as vozes dos participantes dessa interação em uma sequiência de aulas de metodologia de ensino de português como língua segunda na qual o material didático para o ensino de leitura foi elaborado pelos professores indígenas. Os participantes da interação 
CAVALCANTI - É, eu acho que esse livrinho vai ser muito interessante...

são a professora-formadora não-indígena e os professores-alunos indígenas. Há aproximadamente trinta professores pertencentes a oito grupos étnicos diferentes, sendo predominante a etnia Kaxinawá. As línguas nativas desses povos são classificadas como parte de dois grupos lingüísticos: Pano e Aruak.

Organizado e desenvolvido por uma organização nacional não-governamental e nãoreligiosa localizada no Acre, o curso de formação de professores promove encontros anuais com cerca de dois meses de duração no Centro de Formação dos Povos da Floresta.

A pergunta de pesquisa que direciona o presente estudo é: Como os professores indígenas vêem a relação entre as escolas e a construção de identidade étnica? A análise dos dados aponta para um intercâmbio de representações entre a professora-formadora e os professores-alunos na construção do contexto de ensino.

No contexto focalizado, que é sociolingüisticamente complexo, os professores -alunos ou falam a língua indígena e português, ou falam duas línguas indígenas e o português, ou falam somente português. Evidentemente, a questão é mais complexa do que o que se apresenta, pois, no caso do português, há que se considerar o convívio do português introduzido através do material didático nas escolas das aldeias. com a variedade de português falada pelos diferentes grupos étnicos focalizados. Essa variedade é denominada por Maher (1996) como 'português índio' em analogia ao inglês vernacular (Black English) de Labov. Grillo Guimarães se refere a essa variedade como 'português étnico'.

No contexto histórico e sociocultural focalizado, ou seja, no curso de formação de professores, questões/aspectos relacionados ao letramento ${ }^{1}$ são centrais. O período do curso representa um momento de aproximação ${ }^{2}$ à palavra escrita. Alguns desses professoresalunos vêm freqüentando esses cursos anuais desde a década de oitenta e alguns outros estão ali há poucos anos. O desafio do projeto educacional da ONG é trabalhar com professores em - serviço, isto é, que são ao mesmo tempo professores e alunos. As comunidades estão interessadas em ter seus próprios professores educados em um processo de auto-determinação em busca de autonomia, isto é, esses professores, a longo prazo, serão responsáveis por seu próprio sistema de educação, incluindo a formação de professores.

Como adiantei acima, o grupo de professores representa um contexto sociolingüístico complexo. Em outras palavras, há um número de grupos étnicos envolvidos e em cada um desses grupos há proficiência variada nas línguas indígenas e em português. Apoiada em Maher (op.cit.) e Grillo Guimarães (op. cit.), tomei a decisão de considerar esta última como uma segunda língua mesmo nos casos em que a língua indígena não é falada, por exemplo, entre os Apurinã e os Shawãdawa.

O cenário da pesquisa envolve não apenas o que acontece na sala de aula do curso de formação de professores, mas também o que acontece antes e depois das aulas, assim

\footnotetext{
${ }^{1}$ Comissão Pró-Índio do Acre.

Vide Kleiman (1995), Barton (1994), Street (1993) e Gee (1990)

2 De volta às comunidades, as questões de letramento encontram espaço nas escolas, mas não necessariamente fora delas. Os professores, que são também provedores de suas famílias, têm toda uma vida fora da escola que prescinde da escrita.
} 
como o que ocorre no caminho para a sala de aula, durante as refeições, durante as reuniões com os professores-alunos e durante as reuniões com os professores-formadores e em conversas informais que podem acontecer a qualquer momento. Também inclui redirecionamentos baseados nos questionamentos permanentes que ocorrem durante e fora das interações em sala de aula, bem como fora do curso de formação, na volta dos professores formadores às atividades rotineiras em suas universidades de origem.

As mudanças no cenário são perceptíveis tanto no momento em que o pesquisador atua como professor-formador como nos poucos momentos em que se consegue atuar somente como pesquisador e em que se pode exercer a observação em campo distante das urgências do gerenciamento de sala de aula. Por exemplo, nos meus diários de campo é comum encontrar entradas nas quais o professor-formador está profundamente atento às reações dos professores-alunos, mesmo durante momentos informais - quem chega perto, quem permanece mais distante - o pesquisador está sempre tentando examinar as mudanças que ocorrem de um ano para o outro. $\mathrm{O}$ trabalho de campo acontece em um período que varia de uma semana a um mês por ano e, durante esse tempo, os pesquisadores/professoresformadores estão sempre sintonizados ao que é deles esperado como consultores pedagógicos: no ano em que os registros para o estudo em tela foram gerados, nós estávamos envolvidos com o desenho da proposta curricular para o curso de formação de professores. Dessa exposição de como se desenvolve o trabalho de campo, destaca-se o fato de que o tempo precisa ser dividido entre redigir anotações de campo, elaborar material didático e fazer uma leitura atenta e comentada dos textos que os alunos-professores produzem. Se o trabalho de campo para um pesquisador é algo cansativo, imagine-se o que acontece quando se combina pesquisa e ensino. De qualquer modo, sublinha-se aqui que é assim que vejo a pesquisa aplicada que desenvolvo dentro da área de Lingüística Aplicada.

$\mathrm{Na}$ fase do módulo que é o foco deste capítulo, a professora-formadora propôs aos alunos que escrevessem histórias contadas em suas comunidades tanto nas línguas indígenas como em português. Essas histórias, seguidas de atividades de leitura a serem elaboradas ${ }^{3}$ pelos professores-alunos, seriam compiladas em um livreto para ser usado nas escolas das comunidades. É importante registrar que,,além do bem representado grupo étnico Kaxinawá, havia poucos representantes dos outros grupos (Jaminawa, Manchineri, Shawãdawa, Katukina, Asheninka, Apurinã, Yawanawa) e, conseqüentemente, não haveria suficientes histórias escritas nas línguas nativas para montar livretos. Além disso, pelo menos dois dos representantes não falavam sua língua nativa. Fazer um livreto em português era, portanto, uma saída para evitar situações constrangedoras.

\footnotetext{
${ }^{3}$ Os professores-alunos haviam tido aulas intensivas de leitura por duas semanas seguidas antes de as aulas de metodologia de ensino de línguas terem início. Nessas aulas, os professores-formadores haviam chamado a atenção dos professores indígenas para as atividades elaboradas especialmente para o curso de formação. Por exemplo, alguns dos pontos focalizados foram: o uso de aspas e itálicos para mostrar diferentes vozes em um texto. Os professores-formadores também enfatizaram a necessidade de atividades de aquecimento como preparação para leitura e também para a extensão das atividades de leitura em associação com a escrita, com a fala, com o desenho etc como uma forma de atividade pós-leitura.
} 
CAVALCANTI - É, eu acho que esse livrinho vai ser muito interessante...

\section{VOZES NA INTERAÇÃO}

O termo vozes, parte do título deste capítulo, é usada de acordo com Wertsch (1991:13) ( cujo trabalho é baseado em Bakhtin e Vigotsky):

A noção de heterogeneidade faz-nos considerer porque certas formas de falar e pensar (vozes) e não outras são invocadas em algumas ocasiões. Força-nos a reconhecer que não podemos responder esta questão somente com base na metáfora da possessão que focalize naquilo que os humanos 'têm' na forma de conceitos e habilidades. Ao invest disso, devemos considerer como e porque uma voz específica ocupa o palco central, isto é, porque ela é 'privilegiada' (Werstch, 1998) em um cenário específico. ${ }^{4}$

O termo bakthiniano “voz” (originado na análise literária) é elaborado por Graumann (1990:108):

Voz é a consciência expressa que alcança os outros, isto é, é um termo relacional. Um diálogo é a combinação de vozes, é polifônico. As vozes em um diálogosão pessoas conversando 'em concerto', mas uma pessoa engajada em um diálogo não está restrita a uma voz. Ele ou ela pode falar em vozes diferentes assim aumentando o caráter polifônico dos diálogos. ${ }^{5}$

Considerando agora dois momentos nos registros gerados, sendo o primeiro momento em duas cenas, passo a examinar o que acontece na interação. $\mathrm{O}$ extrato abaixo mostra o primeiro dia de aula no módulo de metodologia de ensino de línguas. A professora-formadora apresenta a proposta de elaboração do livreto e parece não encontrar eco ou uma reação favorável para a idéia. Há, no entanto, uma aparente tranqüilidade na interação.

\section{Momento 1 - Cena 1 (Dia 1)}

com as histórias que vocês escreveram, dá pra montar um livrinho pra vocês levarem de volta para as crianças estudarem português...

J: aí eu falei assim, trabalhando com aluno já alfabetizado, né? ...as notícias, né, qualquer informação, então, eles fazem na primeira hora, né? eu chamo pra fazer o jornalzinho, né, então , (...) texto pequeno, né, contando de um companheiro o que aconteceu. e tem muitos textos engraçados, né? e eu achei muito importante isso também. $\mathrm{P}$ (Professora-formadora): ahn, ahn

4 "The notion of heterogeneity calls on us to consider why certain forms of speaking and thinking (voices) rather than others are invoked on particular occasions. It also forces us to recognize that we cannot answer this question simply on the basis of the metaphor of possession, which focuses on what humans 'have' in the way of concepts and skills. Instead, we must consider how and why a particular voice occupies center stage, that is, why it is 'privileged' (Wertsch, 1987) in a particular setting."

5 "Voice is consciousness expressed and reaching others, i.e. it is a relational term.A dialogue is a combination of voices, it is poliphonous. The voices in dialogue are persons speaking 'in concert', but a person engaged in a dialogue is not restricted to one voice. He or she may speak in different voices, thus increasing the poliphonous character of dialogues." 
Trab.Ling.Aplic., Campinas, 44(2) - Jul./Dez. 2005

J:então os alunos já 'tão praticando aí na escrita e na leitura, né?

P: é.

$\mathrm{J}$ : às vezes tem um erro também na palavra ...

P: mas 'cê 'tava pensando em usar esses textos pra preparar atividade de leitura em cima também ...

$\mathrm{J}$ : é tem muitos textos ...

P: é, a gente 'tava pensando que os texto dos mitos são muito difíceis. então o que podia ser usado? ou textos que vocês escrevessem, ou textos que saem no Yumaki [jornal publicado pela ONG de circulação entre as aldeias envolvidas no projeto de educação e saúde], ou textos que os alunos escrevem ... acho que tinha que colecionar um pouco desse material que os alunos escrevem pra trazer aqui, né? vocês acham que é boa idéia ou não? (Pausa) dá pra fazer isso, I?

I: daí, eu trouxe até um bocado que entreguei pra $R$ [da equipe de educação da ONG].

P: Ah, é? (Pausa) então vamos lá. (Pausa)

I (ainda não tinha terminado seu turno): a criançada escreve uma carta pra outra pessoa (Pausa)

P: sei .

I: e cada aluno troca (Pausa)

P: ahn, ahn.

I: e depois cada qual vai ler, só ouvir ...

P: e dá pra usar essas cartas pra fazer outro livro didático, né? o C também tem material de aluno, que aluno escreveu na língua? eles escrevem lá um pouquinho, não escrevem? podia trazer então depois? Júlio tem? não? não tem aqui, não? vocês 'tão entendendo o que eu 'tô querendo dizer? que dá pra montar um livro, como a gente 'tá fazendo esse livreto aqui com as histórias que vocês escreveram, dá pra montar um livrinho pra vocês levarem de volta para as crianças estudarem português? na língua precisamos mais material fácil que a criança possa ler.

A professora-formadora $(\mathrm{P})$ tem uma agenda definida que é: tentar convencer os professores-alunos que é importante elaborar o livreto com os textos e as atividades de leitura. Com este propósito, ela interrompe o turno de dois professores-alunos (J e I) que começam a contar o que eles fazem nas escolas de suas comunidades. Ela busca 'revozear', no sentido porposto por O'Connor \& Michaels (1996) de retomar, as falas dos professores indígenas através do enunciado "Mas 'cê 'tava pensando em usar esses textos pra preparar atividade de leitura em cima também..." Ou seja, ela se apropria do discurso do professor indígena naquilo que é imediatamente relevante para voltar ao tópico que ela introduziu com o objetivo de apresentar e desenvolver a agenda de trabalho proposto. Ela usa diversas estratégias para tomar o turno e o piso conversacional: insere o que parece ser um encorajamento (a $h n, a h n$ ), faz perguntas tentando retomar o tópico (e dá pra usar essas cartas pra fazer outro livro didático, né?) e direciona o turno para outros professoresalunos (o C também tem material de aluno, que aluno escreveu na língua? eles escrevem lá um pouquinho, não escrevem? podia trazer então depois? Júlio tem? não? não tem 
CAVALCANTI - É, eu acho que esse livrinho vai ser muito interessante...

aqui, não?) tentando forçar o encerramento do turno de I e de J. J demonstrou interesse em falar sobre o modo como ele trabalhava com alunos que já sabiam ler e escrever, sobre como ele combinava a leitura e a escrita: tópicos que a professora tinha enfatizado durante a aula de metodologia de ensino. I queria contar sobre uma atividade que ele tinha realizado com seus alunos e que combinava/integrava leitura e escrita. A professora-formadora, no entanto, está determinada a fazer com que os professores-formadores comecem a escrever os textos e a elaborar as atividades de leitura para o livreto neste caso em português e não nas diferentes línguas indígenas.

Na interação acima parece haver um jogo representacional em ação. Utilizo o termo "representações" de acordo com Hall (1997:17):

"Representação é a produção de sentido dos conceitos em nossas mentes através da linguagem. É o elo entre conceitos e linguagem que torna possível fazer referência ao mundo 'real' de objetos, pessoas ou eventos ou mesmo ao mundo imaginário de objetos pessoas ou eventos ficcionais." ${ }^{6}$

Vejo estas representações nas expectativas que são construídas de ambos os lados. Estão nos comentários feitos pela professora-formadora e nas atividades propostas pelos professores-alunos. $^{7}$ Poderia ser inferido aqui que os professores-alunos estão mais preocupados com o contexto imediato de suas salas de aula ao passo que a professoraformadora tem o duplo objetivo de desenvolver a proficiência de leitura dos professoresalunos (focaliza-se nesse curso algo que geralmente é tomado como dado, como já resolvido nos cursos convencionais de formação de professores), e também promover a oportunidade de discussão pedagógica sobre o desenho de atividades de leitura. Em outras palavras, esse objetivo duplo se refere ao desenvolvimento de proficiência lingüística e pedagógica, porém deixando espaço para que eles decidam que pedagogia vão escolher. Além disso, os formadores querem discutir o que está por trás das atividades que são - uma meta-discussão com os professores-alunos - para suas aulas nas escolas das aldeias. Os professores-alunos, por um lado, estão mais interessados em resolver problemas que são mais imediatos para eles como alunos e não como professores. O foco está então em questões diferentes mas relacionadas. Essas vozes que estão fazendo as falas (como diz Bakthin) ecoam as palavras que são faladas em diferentes aulas com diferentes professores no curso de formação. Elas ecoam também os professores-formadores e os professores-alunos em suas discussões na e sobre a sala de aula.

Quando os textos são escritos e chega a hora de elaborar atividades de leitura acontece um outro diálogo semelhante ao apresentado acima. O foco da professora-formadora é meta-metodológico, uma vez que ela convida os professores indígenas para comentar uma

\footnotetext{
6 "Representation is the production of the meaning of the concepts in our minds through language. It is the link between concepts and language which enables us to refer to either the 'real' world of objects, people or events, or indeed to imaginary worlds of fictional objects, people and events.".

${ }^{7}$ Um comentário constante feito pelos professores indígenas é que o que eles estão aprendendo é mais importante para eles enquanto alunos e líderes das comunidades do que para seus alunos que estão aprendendo a ler e escrever nas comunidades.
} 
Trab.Ling.Aplic., Campinas, 44(2) - Jul./Dez. 2005

atividade que foi elaborada para eles próprios enquanto alunos do curso de formação. A atividade tem como objetivo o desenvolvimento de sua proficiência em leitura em português.

\section{Momento 1 - Cena 2 ( Dia 3)}

"Não, Mato Grosso."

P:(...) depois do Item 1 da Pasta Vermelha [Pasta que continha notas sobre o ensino/ aprendizagem de leitura], tem uma atividade aqui. O que vocês acham dessa atividade? (Pausa)

A : Item 1?

P: não, o número 1 mesmo.[A professora lê:] "Agora localize no mapa o estado onde mora o Xavante." foi sobre um texto de leitura como vocês às vezes fazem, né? assim como "agora desenhe o que você entendeu", né? ou "agora mostre no mapa", né? (Pausa longa) depois ela [a professora que havia dado a parte inicial do módulo de língua portuguesa] ela fez perguntas e mais para a frente fez mais perguntas.

A: (incompreensível)

P: oi? Mato Grosso do Sul?

A: não, Mato Grosso.

P: Mato Grosso, né? se vocês continuarem a ler ... estou querendo saber que outro tipo de atividade a $T$ [a professora] fez aí depois dessa de procurar no mapa. (Pausa) no número 2, ela pediu pra explicar uma palavra, não foi? é isso? ela deu uma frase, sublinhou uma parte $e, e, e \ldots$

C: e deixou um pedacinho pra completar ...

P: completar com um sinônimo, né? em outros lugares, ela fez o contrário, não foi? (...)

É importante observar que o que chamou a atenção do professor-aluno na atividade proposta foi apresentar logo uma resposta - Mato Grosso - ao que se pedia na instrução: agora localize no mapa onde mora o Xavante. Os professores-alunos em suas aulas de geografia naquele ano em que os registros foram gerados estavam revisando a matéria sobre a divisão do Brasil em estados. Portanto, a busca pelo local (o estado) onde morava um parente ${ }^{8}$ era mais importante/relevante do que a discussão proposta pelo professorformador sobre o espectro de atividades de leitura. Em outras palavras, os papéis de ser aluno e ser professor não estavam integrados, isto é, pareciam ter vidas separadas.

$\mathrm{O}$ primeiro momento passou, as histórias foram escritas e as atividades de leitura foram elaboradas. Estava então pronto o material para o livreto. Faltava, no entanto, algo a ser feito: o prefácio. Como o tempo do módulo estava se esgotando, e ainda havia esse fechamento a fazer, a professora-formadora se ofereceu para escrever um rascunho e trazêlo para discussão no dia seguinte. Abaixo está a transcrição parcial da última aula que se refere ao exato momento em que o rascunho do prefácio é lido e discutido.

\footnotetext{
${ }^{8}$ Eles se referem a membros de outros grupos étnicos como "parentes".
} 
CAVALCANTI - É, eu acho que esse livrinho vai ser muito interessante...

\section{Momento 2 - Cena Única (Último dia)}

“ È, eu acho que esse livrinho vai ser muito interessante..."

P: [A professora lê o texto outra vez.]

A: está muito melhor assim.

P: tá OK? "Três professores Waiãpi do Estado do Amapá que visitaram o curso também contribuiram com estórias para o livro."

I: está.

A: está pronto.

I: está muito bom.

P: gosta assim?

I: tá ótimo.

T: tudo bem.

A: com este livrinho, do que eu estou vendo aqui, as crianças que sabem mais vão aprender sobre os Waiãpi, por exemplo. assim como a gente: eu mesmo nunca imaginei que eu ia encontrar os Waiãpi. mas com este livrinho, eles vão me perguntar se os Waiãpi realmente existem e vou dizer sim, eles existem. eu vi eles. eu falei com eles. nós trabalhamos juntos para fazer este livrinho."

Muitas vozes ao mesmo tempo: é, é.

P: OK.

A: e as crianças de outros grupos étnicos podem perguntar sobre os Shawãdawa: "eles existem? onde eles moram?"

$\mathrm{P}:$ tá, vamos escrever os nomes dos grupos étnicos no começo ...

$\mathrm{J}$ (que havia estado muito quieto nessa aula diz em voz baixa:) é, esse livrinho vai ser muito interessante.

P: o que que você disse, J?

$\mathrm{J}$ : é, eu acho que esse livrinho vai ser muito interessante. É isso, não é? . Os outros ... meus parentes ...]

A: é concordo com você.

$\mathrm{J}$ : ...vão ter uma surpresa ... eles vão dizer: "estas são as estórias contadas pelos povos de outros grupos étnicos."

A: é, e às vezes é a mesma história, mas contada diferente.

As vozes que surgem mais proeminentemente são aquelas de $\mathrm{J}$ (que tinha estado extremamente quieto durante o módulo daquele ano) e a de A. A voz de J está primeiro muito ausente e depois muito presente no final da interação. Ambas as vozes mostram a construção de identidade étnica através de uma metáfora ontológica da existência de outros povos indígenas. Os professores haviam produzido vários livros didáticos anteriormente, porém, pareciam estar construindo naquele momento uma compreensão de que o livreto iria servir como evidência da existência de outros grupos étnicos além do seu próprio grupo. E esta evidência estava relacionada à palavra escrita, uma ferramenta simbólica que 
eles estavam aprendendo a manejar. Talvez seja esta a explicação para a oração que dá título a este texto: "É, eu acho que esse livrinho vai ser muito interessante." É como se J construísse ou tivesse construído uma agenda que poderia ser explicitada como: "nós somos parte do mundo indígena, mas não sabemos muito uns sobre os outros."

A expressão "Muito interessante" pode indicar a expectativa do que pode acontecer quando J volta a sua comunidade. As crianças podem se sentir motivadas a aprender sobre os outros grupos étnicos. Os adultos ficarão mais interessados em aprender sobre as histórias que eles contam.: "Eles vão dizer: 'Estas são as estórias contadas pelos povos de outros grupos étnicos.

Deve-se observar que os professores indígenas primeiro se preocuparam com a identidade genérica atribuída ao índio no prefácio, mas mesmo então havia a preocupação com a explicitação de todos os grupos étnicos representados no curso. A construção da identidade ${ }^{9}$ étnica, seja ela, pan-étnica ou étnica, é focalizada na interação como um assunto de relevância.

Para Sarup (1996:47):

\begin{abstract}
"Identidade é contraditória e fragmentada. Identidade no pensamento pós-moderno não é uma coisa; o selfé necessariamente incompleto, não terminado - é o 'sujeito em processo' (...) identidade é construída na e através da linguagem. (...) é sempre dentro de representação que nos reconhecemos. Além disso, a identidade está sempre relacionada ao que não se é - o Outro. Devemos nos lembrar que identidade só é concebível na e através da diferença." ${ }^{10}$
\end{abstract}

Cabe neste ponto uma digressão: no caso deste estudo, não se pode prescindir da noção de identidade étnica e sua relação com língua e cultura. E a noção de identidade étnica é aqui utilizada como parte integrante da noção de fronteiras étnicas que constrói e é construída ao redor de um grupo étnico, como aponta Barth (1969).

A construção de representações do que é ser aluno e professor permeia a construção de contexto na interação. Estas construções envolvem as apropriações, no sentido de de Certeau (1996), do discurso do Outro, no caso do professor-formador e no caso dos professores-alunos. Essas apropriações permeiam os objetivos e os interesses dos atores envolvidos neste tipo de interação transcultural, e aponta para conflitos (ou conflitos potenciais) que surgem (ou podem surgir) das diferentes representações e diferentes interpretações.

Sarup associou os conceitos de identidade e representações. Proponho aqui ampliar essa associação em direção ao conceito de posicionamento, termo proposto por Davies

\footnotetext{
${ }^{9}$ Castells (1997: 6) distingue entre identidades e papéis sociológicos (por exemplo, um trabalhador, um pai, um sindicalista etc.).

10 "Identity is contradictory and fractured. Identity in postmodern thought is not a thing; the self is necessarily incomplete, unfinished - it is 'the subject in process'. (...) identity is constructed in and through language. (...) it is always within representation that we recognize ourselves. Moreover, identity is always related to what one is not - the Other. We should remember that identity is only conceivable in and through difference."
} 
CAVALCANTI - É, eu acho que esse livrinho vai ser muito interessante...

\& Harré (1990: 46). O conceito ${ }^{11}$ se refere à posição tomada pelo sujeito que olha o mundo através de uma determinada janela (posição) de acordo com imagens, metáforas, linhas narrativas e conceitos que são tornados relevantes dentro da prática discursiva em que ele está posicionado. Estas práticas podem ser contraditórias e seus produtos podem ser as pessoas elas mesmas. Portanto, um indivíduo emerge através de processos de interação social não como um produto final mas como alguém que é constituído através das várias práticas discursivas nas quais participa. Para os autores, "os seres humanos são caracterizados tanto por sua identidade pessoal como por sua diversidade pessoal descontínua”.

A produção do livreto, que emergiu de um processo de interação social, passou por vários estágios, que na linha de interpretação aqui adotada, mostra a construção de identidades e as representações envolvidas. Nessas representações e construções de identidade, destaca-se o enunciado de A: "É, e às vezes é a mesma história, mas contada diferente...”. A mesma história parece ser uma evidência forte para a identidade pan-étnica. É como se A dissesse: “Todos nós sabemos uma mesma história, portanto, nós temos alguma coisa em comum." Pode-se ainda acrescentar aqui: "Somos parentes." Como as histórias são contadas de modo diferente, há espaço para enfatizar o fator étnico e aqui teríamos A dizendo: "Mas nós temos a nossa maneira e é isso que nos faz diferentes de outros grupos."

\section{CONSIDERAÇÕES FINAIS}

O estudo aqui relatado procura derivar /buscar implicações para a a formação de professores indígenas no Brasil, uma vez que esse tipo de formação é geralmente realizado em um cenário transcultural com não indígenas como formadores e indígenas como professores. A primeira implicação é que mais pesquisa reflexiva do tipo aqui apresentado é necessária. (Sabe-se pouco sobre isso e há sempre uma tendência etnocêntrica de tomar decisões sem levar em conta o ponto de vista dos professores indígenas.) Uma segunda implicação está relacionada à importância de olhar para o professor em salas de aula de cursos de formação para ver o que está por trás da interação estabelecida na construção e modificação de contextos. O jogo de representações (Ver também Cavalcanti, 1999 e 2001b)estabelecido revela a agenda do professor-formador e suas estratégias ou as estratégias usadas para alcançar seus objetivos. Revela ainda diferentes vozes que são importantes para os professores-alunos: as vozes das comunidades Há também implicações (Vide discussão mais ampla em Cavalcanti, 2001a) relacionadas à metodologia de pesquisa para o professor-formador que também trabalha como pesquisador nesse cenário: olhar

\footnotetext{
${ }^{11}$ Harré \& Gillett (1994: 35) afirmam que: "A position then is a set of rights, duties and obligations as a speaker, particularly with respect to what we have called the illocutionary or social force of what one may say. (...) Positioning highlights the importance of 'making something of a situation' as one participates in it and according to one' s perceptions of it. This idea in turn underpins the concept of subjectivity, which expresses the way things appear to be or are signified by the speech and and action of a person in relation to a discursive context."
} 
para si mesmo pode, à primeira vista, representar uma exposição ameaçadora de fragilidades, mas por trás disso está a possibilidade de construir interpretações para o desempenho/ atuação do professor-formador (e como pesquisador - as duas identidades em cheque). Além disso, a questão da transculturalidade (Ver Cox \& Assis-Peterson, em preparação) na interação necessita mais trabalhos de pesquisa para que mais implicações possam ser derivadas para cursos de formação de professores indígenas no país.

\section{REFERÊNCIAS BIBLIOGRÁFICAS}

BAKHTIN, M. (1990). Marxismo e Filosofia da Linguagem. São Paulo: Hucitec.

BARTH, F. (org.) (1969). Ethnic Groups and Boundaries: The Social Organization of Cultural Difference . Boston: Little, Brown and Co.

BARTON, D. (1994). Literacy: An Introduction to the Ecology of Written Language. Oxford: Blackwell.

CASTELLS, M. (1997). The Power of Identity. Oxford: Blackwell.

CAVALCANTI, M.C. (1999). Representaciones sociales en una práctica de lengua escrita: interacción transcultural en un curso de formación de maestros para escuelas de la región occidental de la selva amazónica en Brasil in A.M. Mejía \& L.Tóvar (orgs) Perspectivas recientes del bilingüismo y de la educación bilingüe em Colombia. Editora da Universidad del Valle, Cali, Colômbia,159-180.

. (2001a). A pesquisa do professor como parte da educação continuada em curso de magistério indígena no Acre in A.B. Kleiman (org.) A Formação do Professor: Perspectivas da Lingüística Aplicada. Campinas: Mercado de Letras.

. (2001b). Um evento de letramento, extensão de um curso de formação de professores indígenas como cenário de construção de identidades sociais in A.A. Assis \& M.I.P. Cox (eds) Cenas de Sala de aula: Estudos Etnográficos. Editora da UFMT.

de CERTEAU, M. (1996). A Invenção do Cotidiano: Artes de Fazer. Petrópolis:Vozes (Tradução do francês de obra publicada em 1990. $1^{\text {a }}$ edição brasileira em 1994).

COX, M.I.P. \& ASSIS-PETERSON, A. A. (em preparação). Transculturalidade \& transglossia: para compreender o fenômeno das fricções lingüístico-culturais em sociedades contemporâneas sem nostalgia in M.C. Cavalcanti \& S.M.Bortoni-Ricardo (orgs) Transculturalidade, Linguagem e Educação (em preparação para publicação).

DAVIES, B. \& HARRE, R. (1990). Positioning: The discursive production of selves. Journal for the Theory of Social Behavior, 20/1, 43-63.

GEE, J. P. (1990). Sociolinguistics and Literacies: Ideology in Discourse. Londres: Falmer Press.

GRAUMANN, C. F. (1990). Perspectival structure and dynamics in dialogues in I. Markovà \& K. Foppa (eds) The Dynamics of Dialogue. Harveste/Whetsheaf.

GRILLO GUMARÃES, S. M. (1996). A aquisiição da escrita e diversidade cultural - a prática de professores Xerente. Dissertação de Mestrado inédita. Universidade de Brasília.

HARRÉ, R. \& GILLETT, G. (1994). The Discursive Mind. Londres: Sage. 
CAVALCANTI - É, eu acho que esse livrinho vai ser muito interessante...

KLEIMAN, A. B. (org.) (1995). Os Significados do Letramento: Uma Nova Perspectiva sobre a Prática Social da Escrita. Campinas: Mercado de Letras.

MAHER, T. M. (1996). Ser professor sendo índio: Questões de lingua(em) e identidade. Tese de Doutorado inédita. UNICAMP.

O’CONNOR, M.C. \& MICHAELS, M. (1996). Shifting participant frameworks: orchestrating thinking practices in group discussion in D. Hicks (ed.) Discourse, Learning and Schooling. Cambridge: Cambridge University Press.

SARUP, M. (1996). Identity, Culture and the Postmodern World. Edinburgh: Edinburgh University Press.

STREET, B. (1993). Introduction: the new literacy studies in B. Street (ed.) Cross-cultural Approaches to Literacy. Cambridge: Cambridge University Press.

WERTSCH, J. V. (1991). Voices of the Mind - A Sociocultural Approach to Mediated Action. Cambridge: Harvard.University Press. 